\title{
Balanced Ratio of Concrete Beams Internally Prestressed with Unbonded CFRP Tendons
}

\author{
C. Lee ${ }^{1), *}$, S. Shin ${ }^{2)}$, and H. Lee ${ }^{2)}$ \\ (Received October 9, 2015, Accepted September 28, 2016, Published online December 27, 2016)
}

\begin{abstract}
The compression or tension-controlled failure mode of concrete beams prestressed with unbonded FRP tendons is governed by the relative amount of prestressing tendon to the balanced one. Explicit assessment to determine the balanced reinforcement ratio of a beam with unbonded tendons $\left(\rho_{p f b}^{U}\right)$ is difficult because it requires a priori knowledge of the deformed beam geometry in order to evaluate the unbonded tendon strain. In this study, a theoretical evaluation of $\rho_{p f b}^{U}$ is presented based on a concept of three equivalent rectangular curvature blocks for simply supported concrete beams internally prestressed with unbonded carbon-fiber-reinforced polymer (CFRP) tendons. The equivalent curvature blocks were iteratively refined to closely simulate beam rotations at the supports, mid-span beam deflection, and member-dependent strain of the unbonded tendon at the ultimate state. The model was verified by comparing its predictions with the test results. Parametric studies were performed to examine the effects of various parameters on $\rho_{p f b}^{U}$.
\end{abstract}

Keywords: balanced ratio, carbon-fiber-reinforced polymer, modeling, prestressed concrete, unbonded.

\section{Introduction}

Carbon Fiber Reinforced Polymers (CFRPs) have a number of valuable advantages: corrosion-free; high strength in tension; lower unit weight than steel; and low linear expansion coefficient. As a substitute material for steels, different types of CFRP have been suggested in various applications of concrete structures, mainly for flexure as internal or external CFRP tendons and for CFRP stirrups (Elrefai et al. 2012; Lee et al. 2013; Han et al. 2015; Lee et al. 2015a, b; Girgle and Petr 2016).

Concrete beams prestressed with an insufficient amount of FRP tendons are subject to a catastrophic brittle failure of the beam resulting from a sudden release of elastic energy at the moment of tensile rupture of the FRP tendons. A section is regarded as the tension-controlled section if the FRP tendon rupture governs the beam failure with a prestressing ratio $\left(\rho_{p f}\right)$ less than the balanced ratio of the prestressing tendon $\left(\rho_{p f b}\right)$. On the other hand, if concrete crushing governs beam failure where $\rho_{p f}$ is greater than $\rho_{p f b}$, the section is regarded as the compression-controlled section (ACI 440.1R-03 2003; ACI 440.4R-04 2011).

\footnotetext{
${ }^{1)}$ School of Architecture and Building Science, ChungAng University, Seoul 06974, Korea.

*Corresponding Author; E-mail: cdlee@cau.ac.kr

${ }^{2)}$ Graduate School, Chung-Ang University, Seoul 06974, Korea.

Copyright ( $\odot$ The Author(s) 2016. This article is published with open access at Springerlink.com
}

The balanced reinforcement ratio of bonded FRP tendons $\left(\rho_{p f b}^{B}\right)$ is presented in ACI 440.4R-04 (2011), and was developed based on the compatibility at a section. Linearly varying strength reduction factors were suggested from 0.65 for compression-controlled sections to 0.85 for tension-controlled sections with CFRP (aramid fiber-reinforced polymer) tendons. Determining $\rho_{p f b}^{U}$ becomes more challenging for prestressed beams with unbonded FRP tendons, as the tensile stress of the unbonded tendons depends on the averaged elongation of concrete at the level of unbonded tendons along the beam span (Naaman and Alkhairi 1991a, b; Kato and Hayashida 1993; Maissen and De Semet 1995; Grace et al. 2006, 2008; Du et al. 2008; Heo et al. 2013). Consequently, it is expected that $\rho_{p f b}^{U}$ is always smaller than $\rho_{p f b}^{B}$, and prestressing the beam with a reinforcement ratio of unbodned CFRP tendon $\left(\rho_{p f}^{U}\right)$ greater than $\rho_{p f b}^{B}$ would preserve the compression-controlled section with a higher degree of plasticity, avoiding an abrupt brittle failure. However, this may result in overdesign and underutilize maximum tensile capacity of unbonded tendon. In order to realize a more structurally reliable and yet cost-effective design of prestressed concrete beams with unbonded CFRP tendons, it seems necessary to have a rational evaluation of $\rho_{p f b}^{U}$ available.

An estimation of $\rho_{p f b}^{U}$ is not provided in the ACI 440.4R04 (2011) or any other literature to authors' best knowledge. In this study, modeling of tensile strain of unbonded FRP tendon at ultimate state is presented first and compared with test results of the beam prestressed with unbonded CFRP tendons. Based on the developed iterative algorithms, a practical formula of $\Delta f_{p f u}$ is presented. The model is then modified and the iterative algorithm determining $\rho_{p f b}^{U}$ is presented. 


\section{Equivalent Curvature Blocks at Ultimate State}

\subsection{Assumptions}

Figure 1 shows the load-deflection curves of two typical unbonded-CFRP-prestressed concrete beams tested by Heo et al. (2013). Both beams were post-tensioned with straight CFRP tendons, but reinforced with different types of auxiliary bonded bars: CFRP bars for the TB45 beam and steel bars for the RU50 beam. The experimentally-observed loaddeflection curves are characterized in approximation with the linearly increasing segments between the characteristic points at different loading states: the initial cracking state ("C" in Fig. 1a, b), the yielding state with RU50 beam reinforced with auxiliary bonded steel bars ("Y" in Fig. 1b); and the ultimate state ("U" in Fig. 1(a)). Based on these and other experimental observations (Kato and Hayashida 1993; Maissen and De Semet 1995; Grace et al. 2006, 2008; Heo et al. 2013), the following assumptions were made in the modeling of three equivalent curvature blocks: (1) The curvature distributions can be closely approximated with linear segments between characteristic sections along the span at the ultimate state-first cracked section ("cs"), first yielded section (“ys”) if steel bars with a yielding property were used as auxiliary bonded reinforcement and ultimate section ("us"), as shown in Fig. 1(c); (2) The plane section before deformation remains plane after deformation; (3) The shear deformation is relatively smaller than the flexural deformation and can thus be ignored; and (4) A positive bending moment inducing a positive curvature generates compression and tension, respectively, in the top and bottom fibers of the concrete in a beam section.

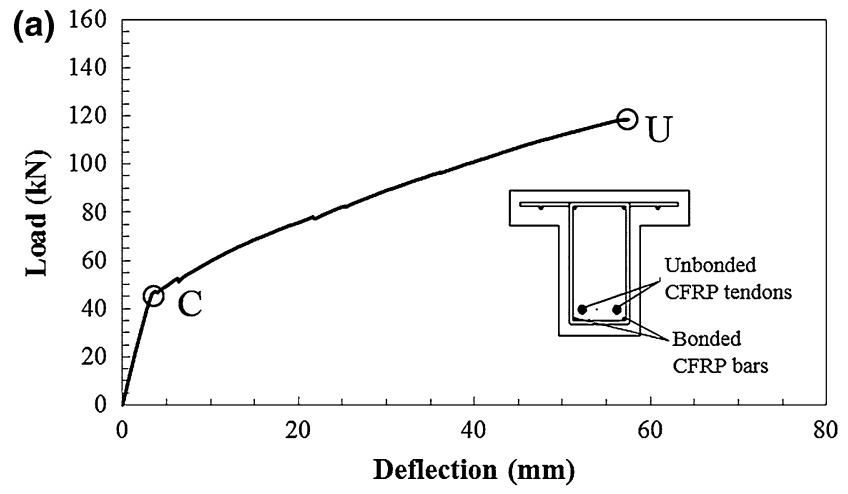

(c)

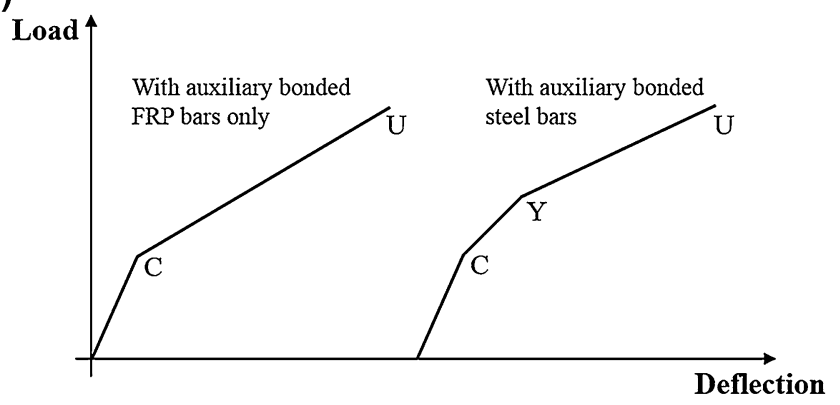

2.2 Equivalent Rectangular Curvature Blocks and Unbonded Tendon Strain

For the beam subjected to 4-point loading (Fig. 2a), the concept of one rectangular equivalent rectangular curvature block (Figs. 3b and 3c) has been used to predict the tensile strain of unbonded steel tendons $\left(\varepsilon_{p f u}\right)$ at the ultimate state (Harajli 1990; Naaman and Alkhairi 1991a, b; Lee et al. 1999). This concept implicitly assumes a linearly-changing deflection of the beam between the support and the loading point, as shown in Fig. 2d. Due to a relatively lower modulus of elasticity than that of steel, relatively larger curvatures and deflections are induced under the same level of flexural load for beams prestressed with CFRP tendons than their counterparts prestressed with steel tendons (ACI 440.4R-04 2011). Should the concept of a single equivalent curvature block be used, a rational assessment of the beam deflection and the member-dependent tensile strain of unbonded CFRP tendons could be hindered due to ignorance of the curvature distributions between the supports and the loading points (Figs. $2 \mathrm{~b}$ and $2 \mathrm{c}$ ).

In order to reflect the contribution of curvature distributions between the support and loading point, three equivalent curvature blocks were assumed in this study. For ultimate loading states ("U" in Fig. 1), the corresponding distributions of moments, linearly-approximated curvatures, and three equivalent curvature blocks along the span are illustrated in Fig. 3a-c, respectively. In Figs. $3 \mathrm{a}$ and $3 \mathrm{~b}$, $M_{\mathrm{sec}}\left(\phi_{\mathrm{sec}}\right)$ denotes the moment (curvature) at a particular section "sec" for the ultimate state, as shown in Fig. 1, where "sec" = "es" for the section at the beam end; "cs" and "ys" for the first-cracked and first-yielded sections,

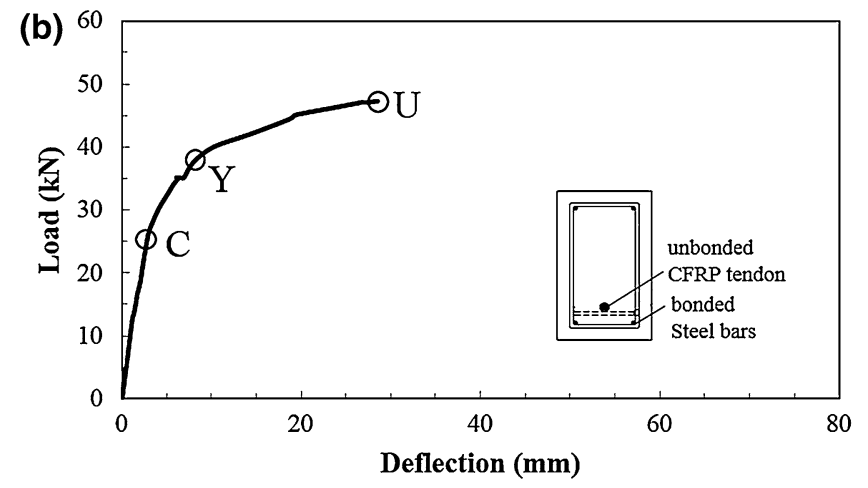

Fig. 1 The experimentally observed and theoretically modeled load-deflection curves of the internally unbonded CFRP prestressed concrete beams. a Beam specimen TB45. b Beam specimen RU50. c Characteristic points in theoretical loaddeflection modeling (not to scale). 
(a)

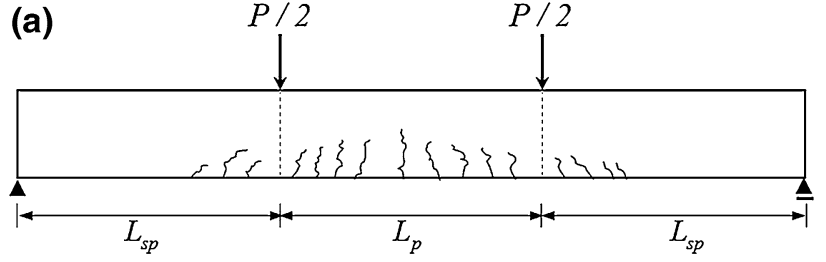

(c)

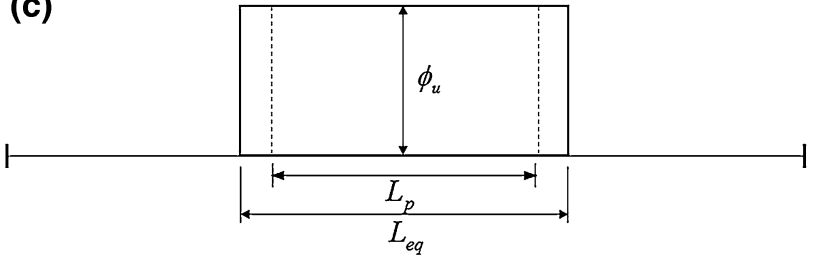

(b)

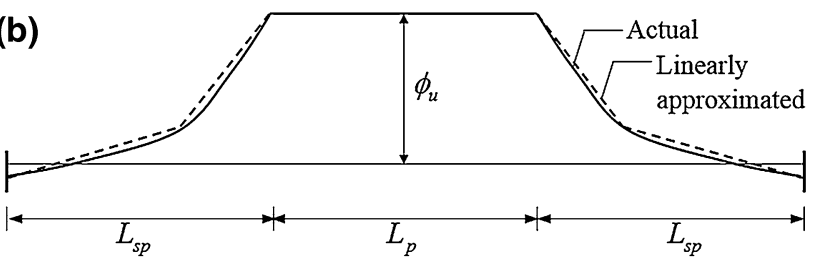

(d)

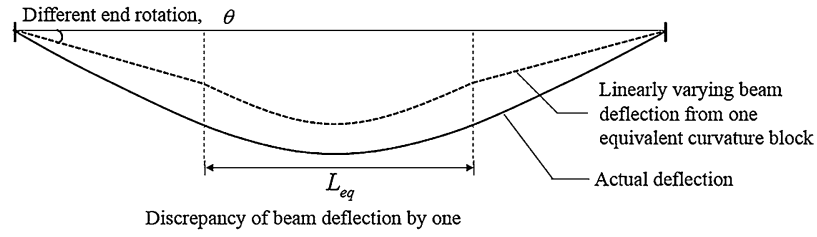

Discrepancy of beam deflection by one

Approximate curvature block in $L_{e q}$

Fig. 2 Approximation by one equivalent curvature block. a Beam under 4-point loading. b Actual and linearly approximated curvature distributions. c One equivalent curvature block. d Deflection of the beam under the assumption of one equivalent curvature block.
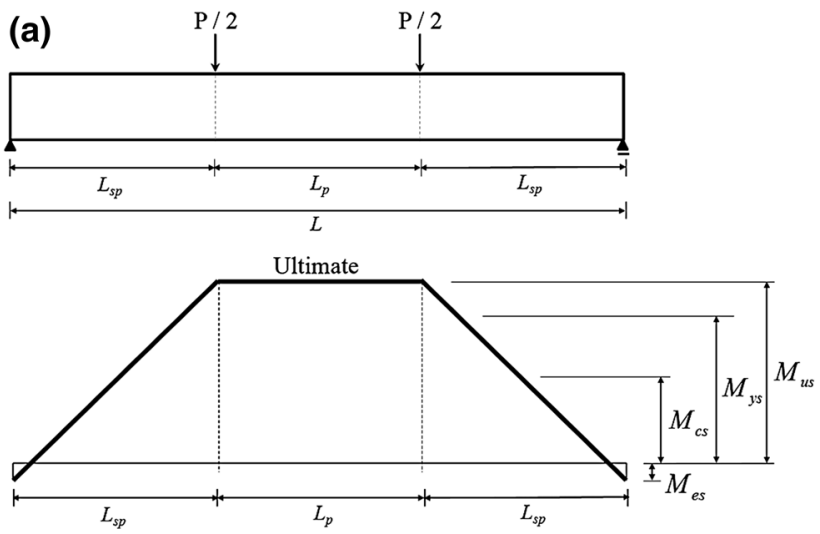

(c)

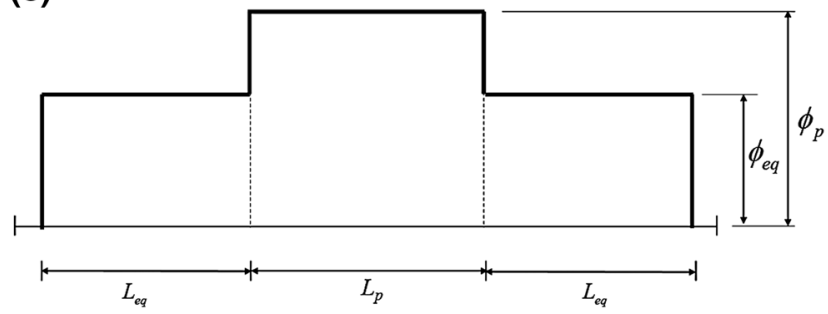

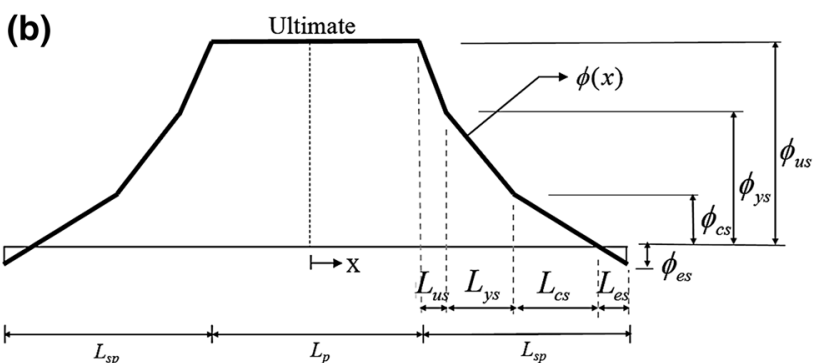

(d)

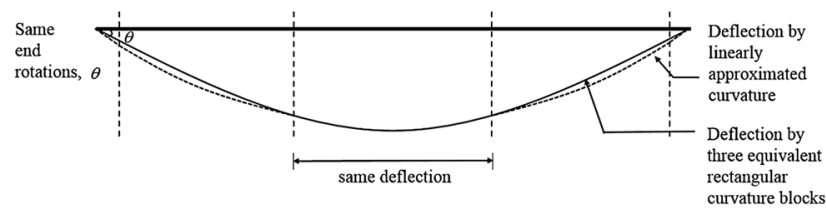

Fig. 3 Moment, curvature distributions and deflections at ultimate state. a Moment distributions. b Linearly approximated curvature distributions. c Three equivalent rectangular curvature blocks. d Close approximations of beam deflection and rotation at support by three equivalent rectangular curvature blocks to those by linearly varying curvatures.

respectively, which were first observed from the beam end; and "us" for the ultimate section.

At the ultimate loading state, one center rectangular curvature block between the loading points with $\phi_{p}$ and $L_{p}$ and two symmetrically-located adjacent rectangular blocks, each with $\phi_{e q}$ and $L_{e q}$, were assumed. The use of three equivalent rectangular curvature blocks enables the approximation of beam deflection between the loading points and rotations at the beam end supports, as a result of which the overall beam deflection could closely approximate that of linearly-varying curvature distributions $\phi(x)$ in Fig. 3b (Fig. 3d). In addition, adopting three rectangular curvature blocks facilitates the integration of curvatures, as this concept assumes the distribution of constant strain at beam sections within a block along the beam span.

For the 4-point loading case, the magnitude $\left(\phi_{e q}\right)$ and length $\left(L_{e q}\right)$ of the adjacent equivalent rectangular curvature blocks between the loading points and supports in Fig. 3c were determined according to Eq. (1).

Deflection based on the linearly varying curvatures is at most cubic polynomial as it can be obtained by integrating linearly varying curvatures twice with respect to beam axis. 
On the other hand, deflection based on three equivalent curvature block is at most quadratic equation. Therefore, Eq. (1) which provides the same beam end rotations and beam deflection between loading points can closely approximate cubically varying deflection of the beam resulting from the linearly varying curvatures.

$$
\phi_{e q} \cdot L_{e q}=\int_{L_{p} / 2}^{L_{p} / 2+L_{s p}} \phi(x) \cdot d x
$$

for the same beam rotation at the supports

$$
\phi_{e q} \cdot L_{e q} \cdot\left(L_{s p}-\frac{L_{e q}}{2}\right)=\int_{L_{p} / 2}^{L_{p} / 2+L_{s p}} \phi(x) \cdot x \cdot d x
$$

for the same beamdeflection in $L_{p}$

where $L_{s p}$ is the distance between the support and loading point (mm).

For the 3-point loading case, $L_{p}=L / 10$ could be used (Lee et al. 1999). It is worth mentioning that the model adjusts the size of the equivalent blocks for a given magnitude of $L_{p}$ so that the beam end rotation and mid-span deflection become the same as those obtained from the linearly varying curvature distributions between characteristic sections.

An evaluation of Eq. (1) results in the following general expressions for $\phi_{e q}$ and $L_{e q}$ :

$$
\phi_{e q}=\frac{3}{4} \cdot \frac{(\Lambda)^{2}}{\Omega} \quad \text { and } \quad L_{e q}=-\frac{2}{3} \cdot \frac{\Omega}{\Lambda}
$$

where $\Lambda=\omega_{e s} \cdot \phi_{e s}+\omega_{c s} \cdot \phi_{c s}+\omega_{y s} \cdot \phi_{y s}+\omega_{u s} \cdot \phi_{u s}$, and $\Omega=\kappa_{e s} \cdot \phi_{e s}+\kappa_{c s} \cdot \phi_{c s}+\kappa_{y s} \cdot \phi_{y s}+\kappa_{u s} \cdot \phi_{u s}$.

The expressions for $\omega_{\mathrm{sec}}$ and $\kappa_{\mathrm{sec}}$ are given in Table 1. In Table 1, values of $L_{s}$ were obtained based on moment distribution in Fig. 3a. Note that $\omega_{\mathrm{sec}}$ and $\kappa_{\mathrm{sec}}$ in Eq. (2) are functions of the unknown strain values of the unbonded CFRP tendon. The amount of additional stress of unbonded tendon depends on the elongations of concrete at the level of the tendon in the $L_{e q}$ region $\left(\Delta_{e q}\right)$ and the $L_{p}$ region $\left(\Delta_{p}\right)$ (Fig. 3c):

$$
\begin{aligned}
\Delta_{e q} & =2 \cdot \int_{L_{p} / 2}^{L_{p} / 2+L_{e q}}\left(\frac{d_{p f}}{c_{e q}}-1\right) \cdot \varepsilon_{e q} \cdot d x \\
& =2 \cdot \phi_{e q} \cdot\left(d_{p f}-c_{e q}\right) \cdot L_{e q}
\end{aligned}
$$

$$
\Delta_{p}=2 \cdot \int_{0}^{L_{p} / 2}\left(\frac{d_{p f}}{c_{u}}-1\right) \cdot \varepsilon_{c u} \cdot d x=\phi_{u} \cdot\left(d_{p f}-c_{u}\right) \cdot L_{p}
$$

where $c_{e q}$ and $\varepsilon_{e q}$ are the depth of the neutral axis from the top compressive concrete fiber $(\mathrm{mm})$ and the compressive strain of the topmost concrete fiber in a section at ultimate state in region $L_{e q}$, respectively.

In Eq. (3a), $c_{e q}$ was obtained from the condition of sectional equilibrium, where the stress-strain relationships of concrete suggested by Kent and Park (1971) was used for compression.

$$
\begin{aligned}
& \int_{0}^{c_{e q}} b(z) \cdot \sigma_{H}(\varepsilon(z)) \cdot d z=A_{p f} \cdot E_{p f} \cdot \varepsilon_{p f u} \\
& \quad+A_{b f} \cdot E_{b f} \cdot \phi_{e q} \cdot\left(d_{b f}-c_{e q}\right)
\end{aligned}
$$

where $A_{p f}$ and $E_{p f}$ are the cross-sectional area $\left(\mathrm{mm}^{2}\right)$ and the modulus of elasticity of the unbonded CFRP tendon ( $M P a)$, respectively, $A_{b f}, d_{b f}$, and $E_{b f}$ are the total sectional area $\left(\mathrm{mm}^{2}\right)$, effective depth $(\mathrm{mm})$, and modulus of elasticity of non-prestressed auxiliary bonded reinforcement $(\mathrm{MPa})$, respectively, $b(z)$ is the width of the beam at $z(\mathrm{~mm}), z$ is the vertical distance measured from the neutral axis to the top of the section $(\mathrm{mm}), \varepsilon(z), \varepsilon_{c o}$ and $\varepsilon_{c r}$ are the concrete compressive strains at $\mathrm{z}(\mathrm{mm} / \mathrm{mm})$, at topmost concrete fiber in a section at maximum stress $(=0.002)$, and at residual stress $\left(=0.2 f_{c}^{\prime}\right)(\mathrm{mm} / \mathrm{mm})$, respectively, $f_{c}^{\prime}$ is the specified compressive concrete strength; and

$$
\sigma_{H}(\varepsilon)=\left\{\begin{array}{ll}
f_{c}^{\prime} \cdot\left[2 \cdot\left(\frac{\varepsilon}{\varepsilon_{c o}}\right)-\left(\frac{\varepsilon}{\varepsilon_{c o}}\right)^{2}\right] & \text { for } 0 \leq \varepsilon \leq \varepsilon_{c o} \\
f_{c}^{\prime} \cdot\left[1-\left(\frac{0.5}{\varepsilon_{c r}-\varepsilon_{c o}}\right) \cdot\left(\varepsilon-\varepsilon_{c o}\right)\right] & \text { for } \varepsilon_{c o}<\varepsilon \leq \varepsilon_{c r} \\
0.2 \cdot f_{c}^{\prime} & \text { for } \varepsilon_{c r}<\varepsilon
\end{array} .(\mathrm{MPa}) .\right.
$$

The $c_{u}$ in Eq. (3b) was obtained from sectional equilibrium at ultimate state with equivalent rectangular compressive stress block provided by ACI Committee 318 (2014). The additional strain of the unbonded FRP tendon $\left(\Delta \varepsilon_{p f u}\right)$ can be assessed by dividing the concrete elongation by the beam span $(L)$ :

$$
\Delta \varepsilon_{p f u}=\frac{\Delta_{e q}+\Delta_{p}}{L}
$$

Table 1 Expressions of multipliers for $\Lambda$ and $\Omega$ in $\phi_{e q}=\frac{3}{4} \cdot \frac{(\Lambda)^{2}}{\Omega}$ and $L_{e q}=-\frac{2}{3} \cdot \frac{\Omega}{\Lambda}$ (Eq. (2)).

\begin{tabular}{c|c|c|c|c}
\hline \multicolumn{2}{c|}{ Sections } & $L_{s}$ & $\omega_{s}$ & \multirow{2}{*}{$\kappa_{s}$} \\
\hline \hline Locations & Symbols (s) & & $L_{e s}$ & $\omega_{e s}\left(3 L_{s p}-L_{e s}\right)$ \\
\hline Beam end & es & $-\frac{M_{e s}}{M_{u s}} L_{s p}$ & $-\left(L_{c s}+L_{u s}\right)$ & $\omega_{c r}\left(L_{c s}+2 L_{y s}+3 L_{u s}\right)$ \\
\hline Cracked section & cs & $\frac{M_{e s}+M_{c s}}{M_{u s}} L_{s p}$ & $-\left(L_{y s}+L_{u s}\right)$ & $\omega_{y s}\left(L_{y s}+2 L_{u s}\right)$ \\
\hline Yield section & ys & $\frac{M_{y s} M_{c s}}{M_{u s}} L_{s p}$ & $-L_{u s}$ & $\omega_{u s} \cdot L_{u s}$ \\
\hline Ultimate section & us & $\left(1-\frac{M_{y s}}{M_{u s}}\right) \cdot L_{s p}$ &
\end{tabular}




\subsection{Moment and Curvature at Characteristic} Sections

The moment and curvature at first cracking section from the beam ends ( $M_{e s}$ and $\phi_{e s}$ in Figs. 3a and 3b, respectively) can be expressed as Eq. (6):

$$
M_{e s}=-A_{p f} \cdot E_{p f} \cdot \varepsilon_{p f u} \cdot e \text { and } \phi_{e s}=\frac{M_{c s}}{E_{c} \cdot I_{c}}
$$

where $E_{c}, I_{c}$ and $e$ are the modulus of elasticity of concrete $(\mathrm{MPa})$, moment of inertia of the section $\left(\mathrm{mm}^{4}\right)$, and the eccentricity of the unbonded tendon $(\mathrm{mm})$, respectively.

Using the modulus of rupture of concrete $\left(f_{r}=0.63 \cdot \sqrt{f_{c}^{\prime}}\right.$ in $\mathrm{MPa}$ ), the magnitude of the internal moment for the cracked section within the region of the maximum moment and the corresponding curvature can be expressed as

$$
\begin{aligned}
& M_{c s}=f_{r} \cdot S_{2}+\varepsilon_{p f u} \cdot A_{p f} \cdot E_{p f} \cdot\left(\frac{r^{2}}{h_{2}}+e\right) \\
& \phi_{c s}=\frac{-A_{p f} \cdot E_{p f} \cdot \varepsilon_{p f u} \cdot e}{E_{c} \cdot I_{c}}+\frac{M_{c s}}{E_{c} \cdot I_{c}}
\end{aligned}
$$

where $h_{2}$ is the height of the cross section (mm), and $S_{2}$ is the section modulus with respect to the bottom surface of the beam $\left(\mathrm{mm}^{3}\right)$.

The moment and curvature at first yielding section from the beam ends ( $M_{c s}$ and $\phi_{c s}$ in Figs. 3a and 3b, respectively) can be found with the yielding of the auxiliary bonded steel bars. The neutral axis depth, $c_{y s}$, was then determined from the sectional equilibrium.

$$
\int_{0}^{c_{y s}} b(z) \cdot \sigma_{H}(\varepsilon(z)) \cdot d z=A_{p f} E_{p f} \varepsilon_{p f u}+A_{b f} f_{b f}
$$

where $f_{b f}$ and $\varepsilon_{c y}$ are the tensile stress of the bonded bar $(\mathrm{MPa})$ and the compressive strains of the topmost concrete fiber in a section at the first yielded section $(\mathrm{mm} / \mathrm{mm})$, respectively.

The moment and curvature at a beam section at which the bonded auxiliary steel bars begin to yield can be obtained once the neutral axis depth, $c_{y s}$, was obtained from Eq. (9):

$$
\begin{aligned}
M_{y s}= & \int_{0}^{c_{y s}} b(z) \cdot \sigma_{H}(\varepsilon(z)) \cdot z \cdot d z+A_{p f} E_{p f} \varepsilon_{p f u}\left(d_{p f}-c_{y s}\right) \\
& +A_{b f} f_{b f}\left(d_{b f}-c_{y s}\right)
\end{aligned}
$$

$$
\phi_{y s}=\frac{\varepsilon_{c y}}{c_{y s}}
$$

At ultimate section, the neutral axis depth, $c_{u s}$, was obtained via an equivalent rectangular compressive stress block (ACI Committee 318, 2014) in sectional equilibrium with the top most concrete compressive strain at its ultimate strain $\left(\varepsilon_{c u}=0.003\right.$ in this study):

$$
\int_{\mathcal{c}_{u s}\left(1-\beta_{1}\right)}^{c_{u s}} 0.85 \cdot f_{c}^{c} \cdot b(z) \cdot d z=A_{p f} E_{p f} \varepsilon_{p f u}+A_{b f} f_{b f}
$$

where $\beta_{1}= \begin{cases}0.85 & 0 \leq f_{c}^{\prime} \leq 28 \mathrm{MPa} \\ 0.85-0.05 \cdot\left(f_{c}^{\prime}-28\right) / 7 & 28 \leq f_{c}^{\prime} \leq 56 \mathrm{MPa} \\ 0.65 & 56 \mathrm{MPa} \leq f_{c}^{\prime}\end{cases}$

Using $c_{u s}$, the moment and curvature corresponding to the region between the loading points with maximum moment were determined by Eq. (11):

$$
\begin{aligned}
M_{u s} & =\int_{c_{u s}\left(1-\beta_{1}\right)}^{c_{u s}} 0.85 \cdot f_{c}^{c} \cdot b(z) \cdot z \cdot d z+A_{p f} E_{p f} \varepsilon_{p f u}\left(d_{p f}-c_{u s}\right) \\
& +A_{b f} f_{p f}\left(d_{b f}-c_{u s}\right)
\end{aligned}
$$

\section{Iterative Algorithm for the Prediction of $\varepsilon_{p f u}$ at Ultimate State}

\subsection{Modified Algorithm to Include Frictional Losses}

In order to find a fixed point of unbonded tendon strain at the ultimate state, equivalent curvature blocks are iteratively refined as given in the following algorithms. The wobble and curvature friction losses associated with current equivalent blocks at ultimate state are included (Nilson 1987; Jeon et al. 2015). In the following, the subscript " $\mathrm{s}$ " represents critical sections ("s" = "cr," "ys," or "us"). A numerical example is given in Appendix 1.

(1) At the beginning of iteration, assume $\Delta \varepsilon_{p f u}$ as a fraction of the difference between the strain of the maximum stress of the CFRP tendon $\left(\varepsilon_{p f m}\right)$ and the sum of the initial prestressing strain $\left(\varepsilon_{p f f}\right)$ and decompression strain $\left(\varepsilon_{d c}\right)$ :

$$
\begin{aligned}
& \Delta \varepsilon_{p f u, s}=\alpha \cdot\left\{\varepsilon_{p f m}-\left(\varepsilon_{p f i}+\varepsilon_{d c}\right)\right\}, 0.0 \leq \alpha \leq 1.0 \\
& \varepsilon_{p f u, s, o}=\varepsilon_{p f i}+\varepsilon_{d c}+\Delta \varepsilon_{p f u, s}
\end{aligned}
$$

(2) Using $\varepsilon_{p f u, s, o}$, evaluate $\left(M_{e s}, \phi_{e s}\right),\left(M_{c s}, \phi_{c s}\right),\left(M_{y s}\right.$, $\left.\phi_{y s}\right)$, and $\left(M_{u s}, \phi_{u s}\right)$ based on Eqs. (6), (7), (9), and (11), respectively. Then obtain the characteristic lengths from Table 1.

(3) From Eq. (2), obtain $\phi_{e q}$ and $L_{e q}$. From Eq. (5), find $\Delta \varepsilon_{p f u}=\frac{\Delta_{e q}+\Delta_{p}}{L}$.

(4) Obtain the revised $\Delta \varepsilon_{p f u, s}$ resulting from the losses by wobble friction $(\kappa)$ and curvature friction $(\eta)$.

$\theta_{s}=\left\{\begin{array}{lr}\frac{1}{2} \cdot \phi_{u} \cdot L_{p}\left(=\theta_{u s}\right) & \text { for ultimate section } \\ \phi_{u}+\int_{L_{p} / 2}^{L_{s}} \phi_{e q} \cdot\left\langle\frac{L_{s}-L_{p} / 2}{L_{e q}}-1\right\rangle \cdot d x & \text { for other sections }\end{array}\right.$

$$
\Delta \varepsilon_{p f u, s}=e^{-\left(\kappa \cdot L+\eta \cdot \theta_{s}\right)} \cdot \Delta \varepsilon_{p f u}
$$

where, $<E>=\left\{\begin{array}{cl}L_{e q} & \text { if } E \geq 0 \\ L_{s} & \text { if } E<0\end{array}\right.$ 
(5) Find the updated value of $\varepsilon_{p f u, s, n}$ for each critical section by:

$\varepsilon_{p f u, s, n}=\varepsilon_{p f i}+\varepsilon_{d c}+\Delta \varepsilon_{p f u, s}$

(6) If $\max \left|\frac{\varepsilon_{p f u, s, n}-\varepsilon_{p f u, s, o}}{\varepsilon_{p f u, s, o}}\right| \leq$ tolerance, then the strain of the unbonded tendon is converged with $\varepsilon_{p f u, s}=\varepsilon_{p f u, s, n}$. Otherwise, let $\varepsilon_{p f u, s, o}=\varepsilon_{p f u, s, n}$ and repeat from step 2).

For a wide range of the initially assumed values of the additional strain for the unbonded tendon ( $\alpha$ in Eq. (12) between 0 and 1.0), the model showed stability by converging to the identical values of $\varepsilon_{p f u}$ within two to four iterations as can be seen in Fig. 4 for all cases with or without frictional loss. In order to investigate the effect of friction on strain increment, a relatively conservative value of $\kappa=0.0015 / \mathrm{m}$ for wobble friction and $\eta=0.264 / \mathrm{rad}$. provided by $\mathrm{Yu}$ and Zhang (2011) were used. It was found that only a marginal difference of $1 \%(5 \%)$ for total strain (strain increment) was observed due to frictional loss. Therefore, no further frictional effect is included in subsequent analysis.
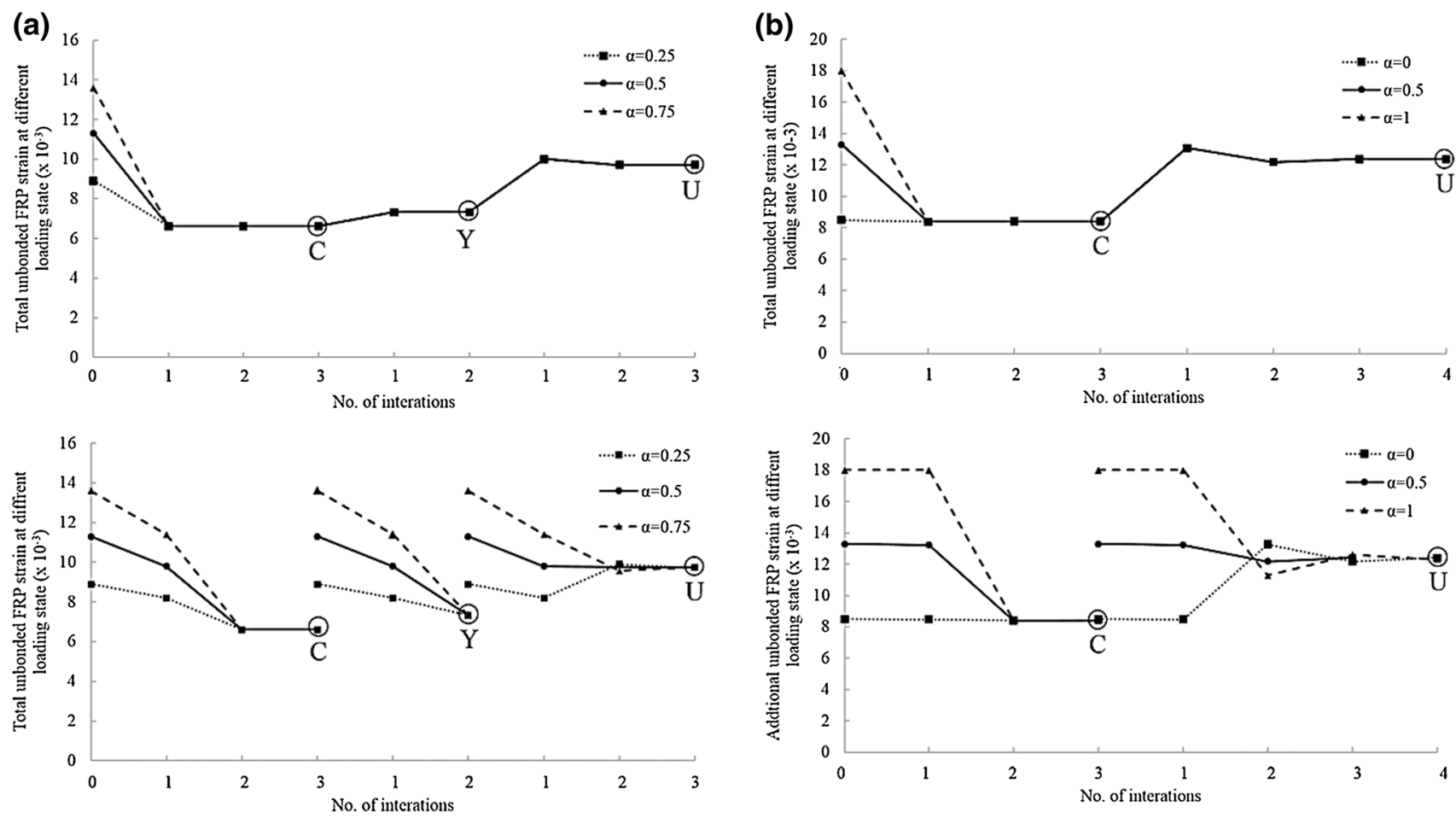

Fig. 4 Examples of convergence trend of the model prediction with two different ways: $\alpha$ in Eq. (12a) given in the initial cracking state only; and the same $\alpha$ assigned at the beginning stage of each state. a RU50. b TO45.

Table 2 Mechanical properties of tendons, auxiliary bonded reinforcement and stirrup.

\begin{tabular}{|c|c|c|c|c|c|c|c|}
\hline \multirow{2}{*}{\multicolumn{2}{|c|}{ Types }} & \multirow{3}{*}{$\begin{array}{c}\text { Diameter }(\mathrm{mm}) \\
7.5\end{array}$} & \multirow{3}{*}{$\begin{array}{c}\begin{array}{c}\text { Effective area } \\
\left(\mathrm{mm}^{2}\right)\end{array} \\
30.4\end{array}$} & \multirow{2}{*}{\multicolumn{3}{|c|}{ CFRP }} & \multirow{3}{*}{$\begin{array}{c}\text { Steel } \\
\begin{array}{c}f_{y} \\
(\mathrm{MPa})\end{array} \\
-\end{array}$} \\
\hline & & & & & & & \\
\hline Tendons & CFCC & & & $\begin{array}{c}f_{p f m} \text { or } f_{b f m} \\
(\mathrm{MPa})\end{array}$ & $\begin{array}{c}\begin{array}{c}E_{p f} \text { or } E_{b f} \\
(\mathrm{MPa})\end{array} \\
144,000\end{array}$ & $\begin{array}{c}\begin{array}{c}\varepsilon_{p f m} \text { or } \varepsilon_{b f m} \\
(\%)\end{array} \\
1.30\end{array}$ & \\
\hline & & 10.5 & 55.7 & 1880 & 144,000 & 1.30 & - \\
\hline & & 15.2 & 113.6 & 1750 & 135,000 & 1.30 & - \\
\hline & DWC & 9.5 & 70.9 & 2500 & 135,000 & 1.85 & - \\
\hline \multirow[t]{2}{*}{ Auxiliary bars } & DWC & 6.0 & 28.3 & 2200 & 139,000 & 1.58 & - \\
\hline & Steel & 6.0 & 31.6 & - & - & - & 420 \\
\hline \multirow[t]{2}{*}{ Stirrups } & DWC & 6.0 & 28.3 & 2200 & 139,000 & 1.58 & - \\
\hline & Steel & 6.0 & 31.6 & - & - & - & 420 \\
\hline
\end{tabular}

$f_{p f m}$ : tensile strength of CFRP tendons $(\mathrm{MPa}) ; f_{b f m}$ : tensile strength of non-prestressed auxiliary bonded reinforcements $(\mathrm{MPa})$. 


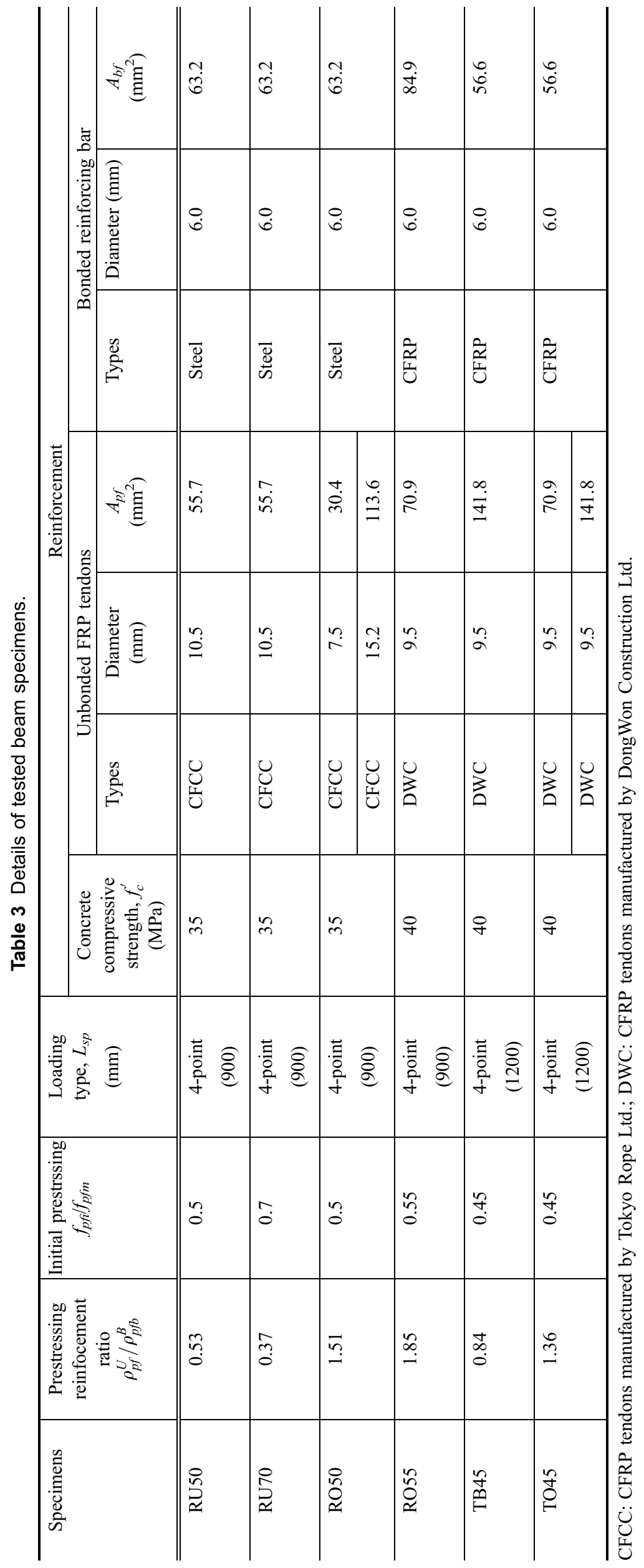

International Journal of Concrete Structures and Materials (Vol.11, No.1, March 2017) | 7 


\subsection{Validity of the Model}

The validity of the model was examined by comparing its predictions with those from the tested beams reported in the authors' previous study (Lee et al. 2015a, b). As the details of tested prestressed beams with unbonded CFRP tendons have been reported elsewhere (Heo et al. 2013), the discussion herein is focused primarily on comparisons between model predictions and test results on flexural capacity and at the ultimate state of the tested beams. The mechanical properties of the materials and the details of the tested beams are presented in Tables 2, 3, and Fig. 5. In Table 4 and Fig. 6, comparisons between model predictions and test results for flexural load capacity and unbonded tendon strain are presented. Gage readings from beams RU70 and TB45 are not included in the comparison, as their values, presumably hampered by the friction between the gages and the surrounding concrete, were erroneous.

The model was able to predict an ultimate load capacity for the tested specimens with reasonable accuracy regardless of the sectional shape, prestressing reinforcement ratio,
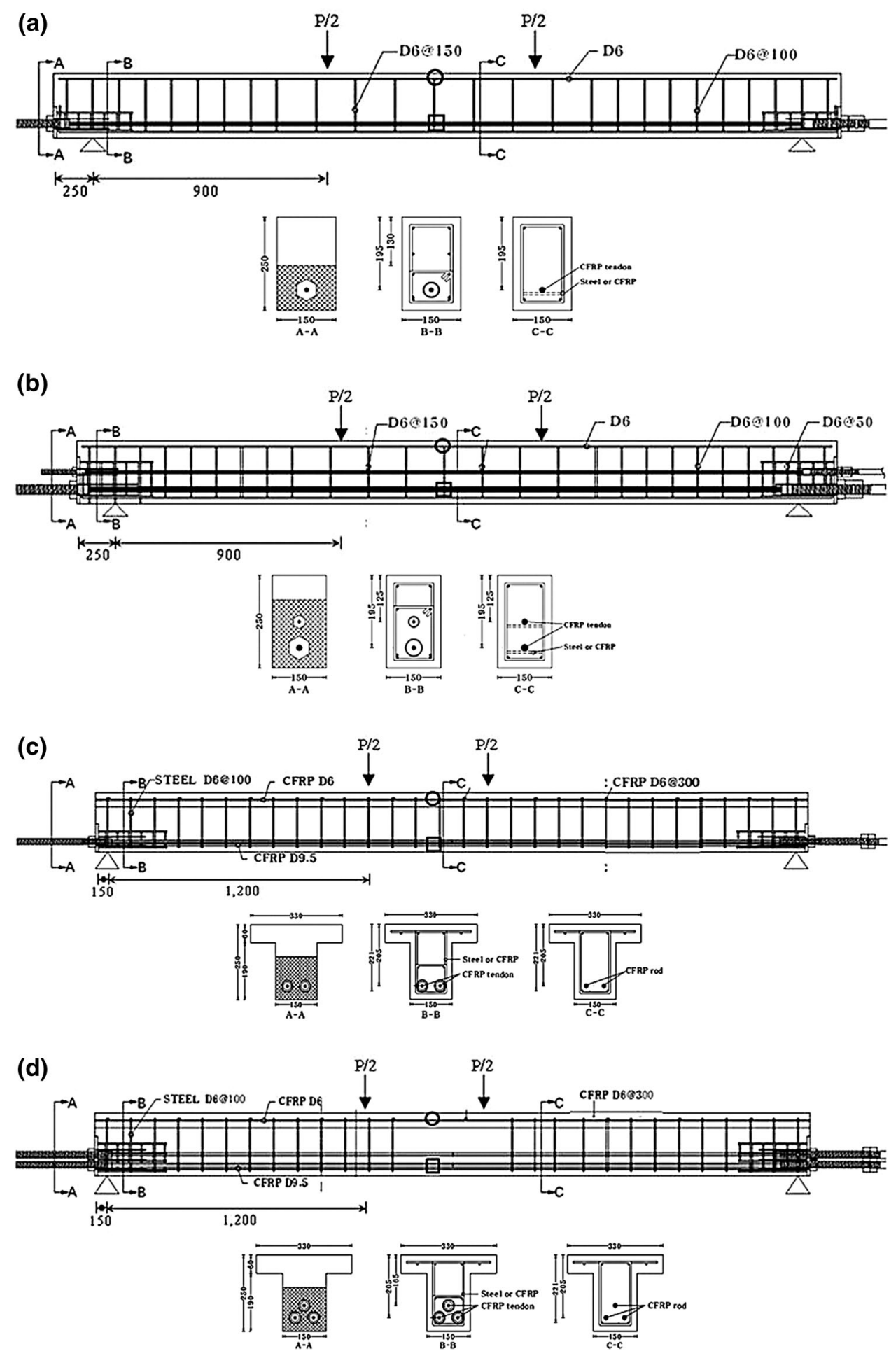

Fig. 5 Beam specimens ("open circle" for concrete strain gages and "open square" for unbonded CFRP tendon strain gages). a RU50, RU70, or RO55. b RO50. c TB45. d TO45. 

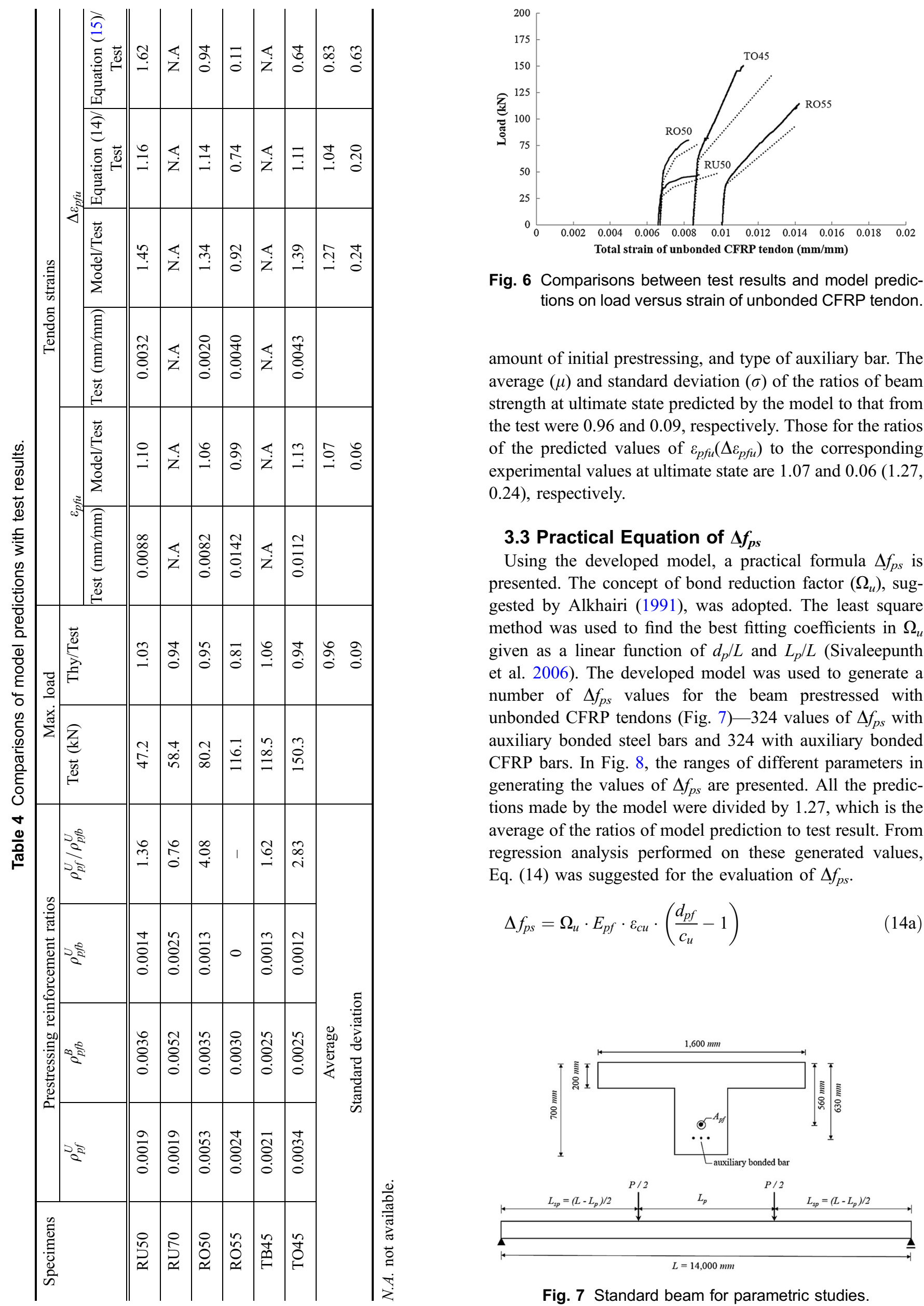

Fig. 6 Comparisons between test results and model predictions on load versus strain of unbonded CFRP tendon.

amount of initial prestressing, and type of auxiliary bar. The average $(\mu)$ and standard deviation $(\sigma)$ of the ratios of beam strength at ultimate state predicted by the model to that from the test were 0.96 and 0.09 , respectively. Those for the ratios of the predicted values of $\varepsilon_{p f u}\left(\Delta \varepsilon_{p f u}\right)$ to the corresponding experimental values at ultimate state are 1.07 and 0.06 (1.27, $0.24)$, respectively.

\subsection{Practical Equation of $\Delta f_{p s}$}

Using the developed model, a practical formula $\Delta f_{p s}$ is presented. The concept of bond reduction factor $\left(\Omega_{u}\right)$, suggested by Alkhairi (1991), was adopted. The least square method was used to find the best fitting coefficients in $\Omega_{u}$ given as a linear function of $d_{p} / L$ and $L_{p} / L$ (Sivaleepunth et al. 2006). The developed model was used to generate a number of $\Delta f_{p s}$ values for the beam prestressed with unbonded CFRP tendons (Fig. 7)-324 values of $\Delta f_{p s}$ with auxiliary bonded steel bars and 324 with auxiliary bonded CFRP bars. In Fig. 8, the ranges of different parameters in generating the values of $\Delta f_{p s}$ are presented. All the predictions made by the model were divided by 1.27 , which is the average of the ratios of model prediction to test result. From regression analysis performed on these generated values, Eq. (14) was suggested for the evaluation of $\Delta f_{p s}$.

$$
\Delta f_{p s}=\Omega_{u} \cdot E_{p f} \cdot \varepsilon_{c u} \cdot\left(\frac{d_{p f}}{c_{u}}-1\right)
$$
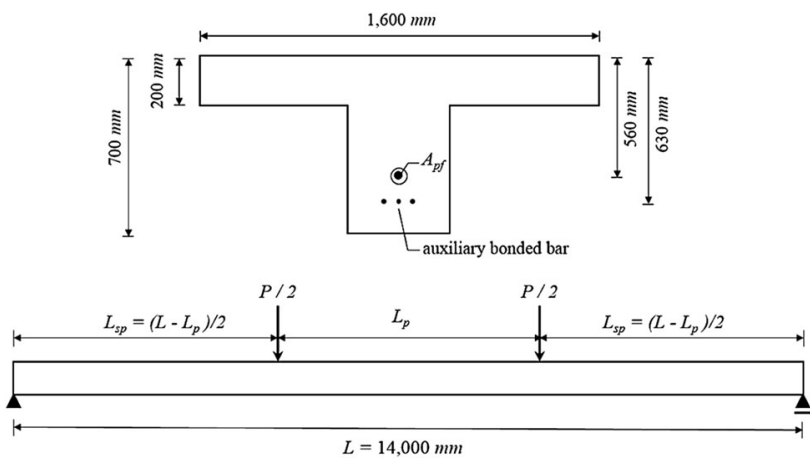

Fig. 7 Standard beam for parametric studies. 

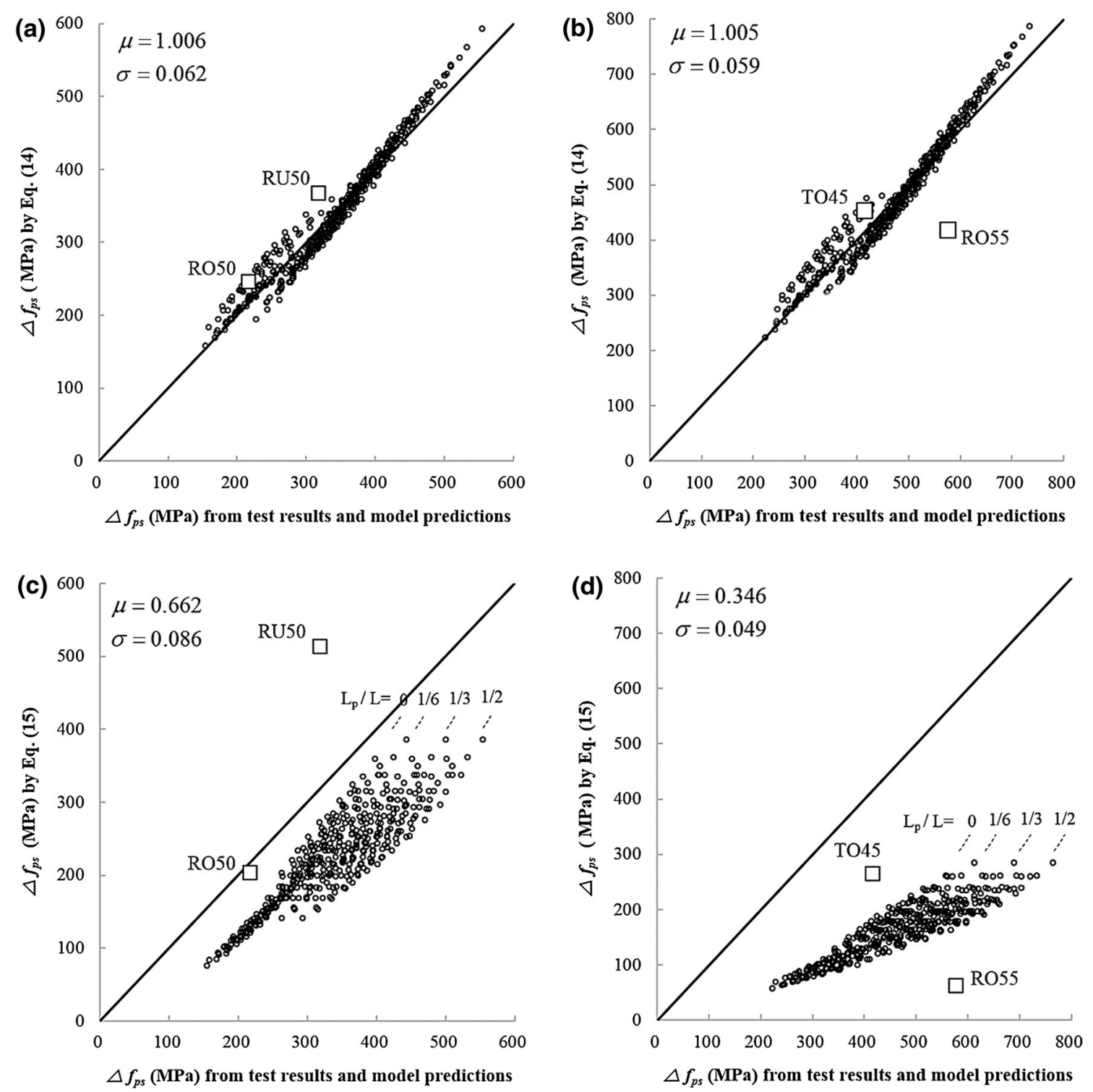

Fig. 8 Comparisons of $\Delta f_{p s}$ : test results and predictions by three equivalent curvature block model versus predictions by Eqs. (14) or (15) $\left(30 \mathrm{MPa} \leq f_{c}^{\prime} \leq 50 \mathrm{MPa}, 0.4 \leq f_{p f i} / f_{p f m} \leq 0.6,525 \mathrm{~mm} \leq d_{p f} \leq 575 \mathrm{~mm} 1.0 \leq A_{b f} / A_{b f, \min } \leq 2.0,0 \leq L_{p} / L \leq 0.5\right.$, $1.0 \leq \rho_{p d}^{U} \rho_{p f b}^{B} \leq 1.2$ ). a Equation (14) for beams with auxiliary bonded steel bars. $\mathbf{b}$ Equation (14) for beams with auxiliary CFRP bars. $\mathbf{c}$ Equation (15) for beams with auxiliary bonded steel bars. d Equation (15) for beams with auxiliary CFRP bars.

$$
\Omega_{u}= \begin{cases}1.80 \cdot \frac{d_{p}}{L}+0.47 \cdot \frac{L_{p}}{L}+0.14 & \text { for auxiliary bonded steel bars } \\ 2.15 \cdot \frac{d_{p}}{L}+0.64 \cdot \frac{L_{p}}{L}+0.21 & \text { for auxiliary bonded CFRP bars }\end{cases}
$$

Equation (15) is suggested in ACI 440.4R-04 (2011) for the prediction of $\Delta f_{p s}$ of the unbonded FRP tendon at ultimate state.

$$
\Delta f_{p s}= \begin{cases}\frac{1.5}{\left(L / d_{p f}\right)} \cdot E_{p f} \cdot \varepsilon_{c u} \cdot\left(\frac{d_{p f}}{c_{u}}-1\right) & \text { for } 1 \text { - point mid - span loading } \\ \frac{3.0}{\left(L / d_{p f}\right)} \cdot E_{p f} \cdot \varepsilon_{c u} \cdot\left(\frac{d_{p f}}{c_{u}}-1\right) & \text { for } 4 \text { - point or uniform loading }\end{cases}
$$

As can be seen in Table 4, Eq. (14) was able to predict test results with a reasonable accuracy. The $\mu$ and $\sigma$ for the ratios of prediction made by Eq. (14) to test result are 1.04 and
0.20 , respectively. However, rather scattered predictions were made by Eq. (15) with 0.83 and 0.63 for the $\mu$ and $\sigma$, respectively. Figure 8 exhibits that better predictions were made by Eq. (14) than Eq. (15) for both values of $\Delta f_{p s}$ from test result and model prediction. Similar trends in predicting $\Delta f_{p s}$ are shown between Eqs. (14) and (15): overestimation for RU50 and underestimation of RO55. It is worth mentioning that Eq. (15) was empirically suggested by Alkhairi (1991) for concrete beams with unbonded steel tendons in such a way that most of the predicted values are smaller than the experimental results. As a result, Eq. (15) estimated rather conservative values of $\Delta f_{p s}$ for the beams with auxiliary bonded steel bars, compared with those from the test results and three equivalent curvature block model (Fig. 8c). In addition, Eq. (15) for 4-point loading case was empirically developed mostly based on the third point test results 
for the beams with unbonded steel tendons and auxiliary bonded steel bars. Consequently, Eq. (15) resulted in a significant deviation from model predictions and test results when it predicted the values of $\Delta f_{p s}$ for the beams with auxiliary bonded CFRP bars (Fig. 8d). Equation (15) was also shown to disregard the effect of $L_{p} / L$ on $\Delta f_{p s}$.

\section{Iterative Algorithm for the Determination of $\rho_{p f b}^{U}$}

\subsection{Development of a Balanced Ratio}

Based on the compatibility between concrete and CFRP tendon strains, $\rho_{p f b}^{B}$ can be given by Eq. (16):

$$
\rho_{p f b}^{B}=\frac{0.85 \cdot \alpha_{1} \cdot \beta_{1}}{\left(1+\alpha_{2}\right)}-\rho_{b f} \cdot \alpha_{3}
$$

where $\alpha_{1}=\frac{f_{c}^{\prime}}{f_{p f m}}, \alpha_{2}=\frac{\varepsilon_{p f m}-\varepsilon_{p f i}-\varepsilon_{d c}}{\varepsilon_{c u}}, \alpha_{3}=\frac{f_{b f}}{f_{p f m}}, \rho_{b f}=\frac{A_{b f}}{b \cdot d_{p f}}$, and $f_{p f m}$ is the tensile strength of CFRP tendons (MPa).

For the balanced concrete beam prestressed with unbonded tendon, tendon strain reaches its maximum value, $\varepsilon_{p f m}$, at ultimate state:

$$
\varepsilon_{p f i}+\varepsilon_{d c}+\left(\Delta_{e q}+\Delta_{p}\right) / L=\varepsilon_{p f m}
$$

A substitution of $\Delta_{e q}$ and $\Delta_{p}$ in Eq. (3) into Eq. (17) results in a $\rho_{p f b}^{U}$ as given in Eq. (18):

$$
\begin{aligned}
\rho_{p f b}^{U}= & \frac{0.85 \cdot \alpha_{1} \cdot \beta_{1}}{1+\frac{L}{L_{p}} \cdot\left[\alpha_{2}-2\left(d_{p f}-c_{e q}\right) \cdot\left(\frac{\phi_{e q}}{\varepsilon_{c u}}\right) \cdot\left(\frac{L_{e q}}{L}\right)\right]}-\rho_{b f} \\
& \cdot \alpha_{3}
\end{aligned}
$$

In order to reflect their member dependency of $\phi_{e q}, L_{e q}$ and $c_{e q}$ in Eq. (18), $\rho_{p f b}^{U}$ was obtained by repeatedly renewing the values of $\phi_{e q}, L_{e q}$ and $c_{e q}$ in two loops. The following iterative scheme is employed:

(1) Assume $\rho_{p f b}^{U}=0.5 \cdot \rho_{p f b}^{B}$

(2) Let $\Delta \varepsilon_{p f u, o}=\varepsilon_{p f m}-\varepsilon_{p f i}-\varepsilon_{d c}$ and $\varepsilon_{p f u, o}=\varepsilon_{p f m}$

(3) Obtain $A_{p f}=\rho_{p f b}^{U} \cdot b \cdot d_{p f}$

(4) Estimate the tensile force of the tendon by $T_{p f}=A_{p f}$. $E_{p f} \cdot \varepsilon_{p f u, o}$. Obtain the $L_{e q}$ and $\phi_{e q}$ from Eq. (2).

(5) Obtain the updated value of $\Delta \varepsilon_{p f u, n}$ from Eq. (5). Find the renewed unbonded tendon strain by $\varepsilon_{p f u, n}=\varepsilon_{p f i}+\varepsilon_{d c}+\Delta \varepsilon_{p f u, n}$.

(6) If $\mid \frac{\varepsilon_{p f u, n}-\varepsilon_{p f u, o}}{\varepsilon_{p f u, o}} \leq$ tolerance, then let $\varepsilon_{p f u}=\varepsilon_{p f u, n}$ and go to step 7). Otherwise, let $\varepsilon_{p f u, o}=\varepsilon_{p f u, n}$ and repeat from step 4).

(7) If $\left|\frac{\varepsilon_{p f u}-\varepsilon_{p f n}}{\varepsilon_{p f m}}\right| \leq$ tolerance, then the $\rho_{p f b}^{U}$ is converged and stop. Otherwise, update $\rho_{p f b}^{U}$ in Eq. (18) using the revised values of $\phi_{e q}, L_{e q}$ and $c_{e q}$. Repeat from step 3).

\subsection{Estimation of $\rho_{p f b}^{U}$ and Failure Modes for Tested Beams}

For each tested beam, evaluated values of $\rho_{p f b}^{B}$ using Eq. (16) and $\rho_{p f b}^{U}$ via the above algorithms are presented in
Table 4. All tested beams presented in Table 4 except for beam RU70 are shown to be compression-controlled sections with a $\rho_{p f}^{U}$ greater than the corresponding $\rho_{p f b}^{U}$. Note that the $\rho_{p f}^{U}$ s of beams RU50, RU70 and TB45 are less than the corresponding $\rho_{p f b}^{B}$ s. The beam RO55 was found to reach its ultimate state without tensile fracture regardless of the sectional area of unbonded tendon due to a relatively large sectional area of the auxiliary bars.

From Table 4, it can be seen that the average of the ratios of theoretically estimated $\varepsilon_{p f u}$ values to experimentally obtained ones is 1.07. A more conservative $\rho_{p f b}^{U}$ is, therefore, implied by the model with its greater prediction on the tensile strain of unbonded tendon. From experiments, it was observed that all of the tested beams, including the underreinforced RU70 beam with a ratio of $\rho_{p f}^{U} / \rho_{p f b}^{U}$ equal to 0.76 , failed in compression-controlled mode by the concrete crushing without tensile fracture of the unbonded tendons (Heo et al. 2013).

For the under-reinforced beam RU70, if the strain of the unbonded tendon increases over its $\varepsilon_{p f m}$ without fracture at the ultimate state, the developed model predicts the strain value at the ultimate state corresponding to the 1.05 times $\varepsilon_{p f m}$. This increase in tendon strain seems to be relatively marginal compared with the provided sectional area of the tendon, which was $24 \%$ less than the sectional area for the balanced condition. The compression-controlled failure in beam RU70 can be explained by the marginally increasing tendon strain over $\varepsilon_{p f m}$ even for relatively small $\rho_{p f}^{U} / \rho_{p f b}^{U}$ in conjunction with the conservative overestimation of the model for the tendon strain.

\section{Parametric Studies for $\rho_{p f b}^{U}$}

Using the developed model, the effects of $f_{c}^{\prime}, f_{p f i}, d_{p f u}, A_{b f}$ and $L_{p} / L$ on $\rho_{p f b}^{U}$ were studied. Figure 7 and Table 5 present the standard beam geometry and the ranges of different parameters, respectively. Beams having auxiliary bonded CFRP bars only were considered.

\subsection{Effect of $f_{c}^{\prime}$}

Figure 9(a) illustrates that an increase in $f_{c}^{\prime}$ results in an almost proportional increase in the values of $\rho_{p f b}^{B}$ and $\rho_{p f b}^{U}$. For the section with bonded tendons, the strain configuration of concrete through the depth of the beam section is predetermined by the difference in $\varepsilon_{p f m}$ and $\varepsilon_{p f i}$ of the tendon. As a result, an increase (decrease) in the sectional area of tendon is needed when concrete compressive strength increases (decreases). The tensile strain of the auxiliary bonded re-bars remains the same irrespective of concrete compressive strengths due to a predetermined strain configuration. A similar explanation can also be applicable to a section prestressed with unbonded tendons. Compared with a counterpart section with bonded tendon, a section with unbonded tendon would have reduced neutral axis depth, which results in relatively larger strains of concrete at the level of tendon and auxiliary bonded bars. 


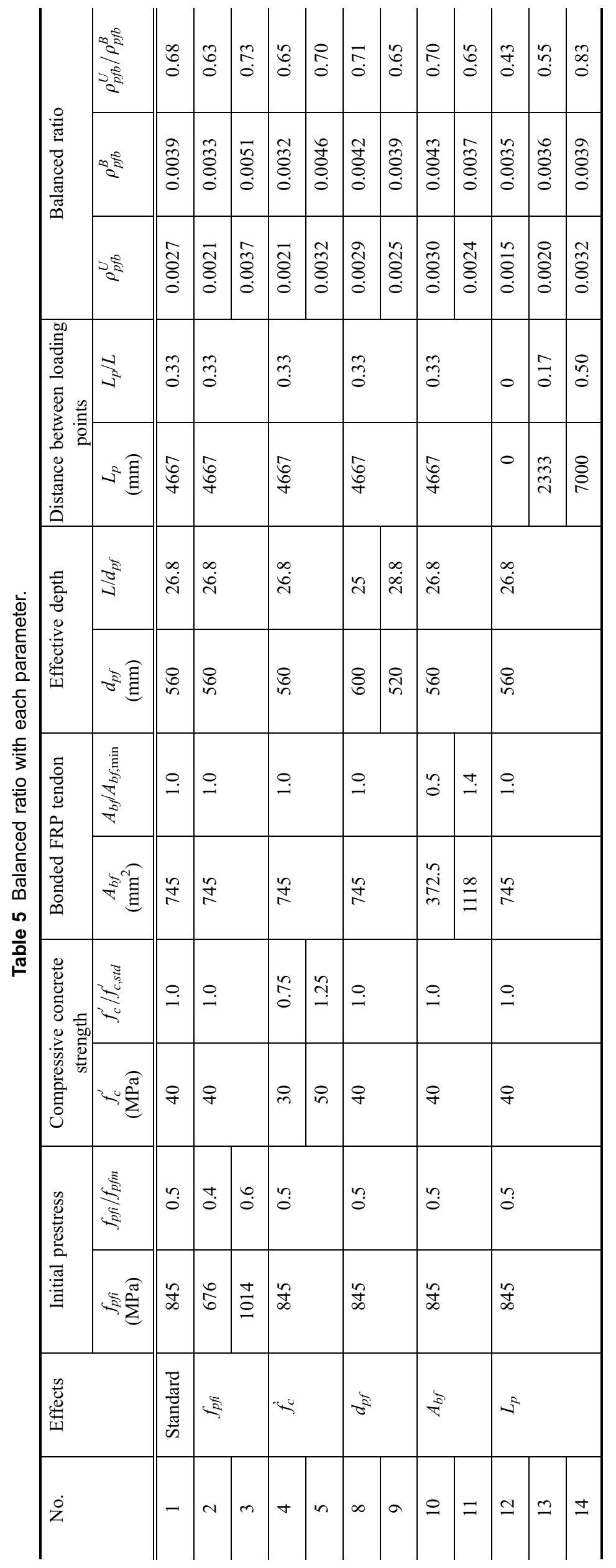



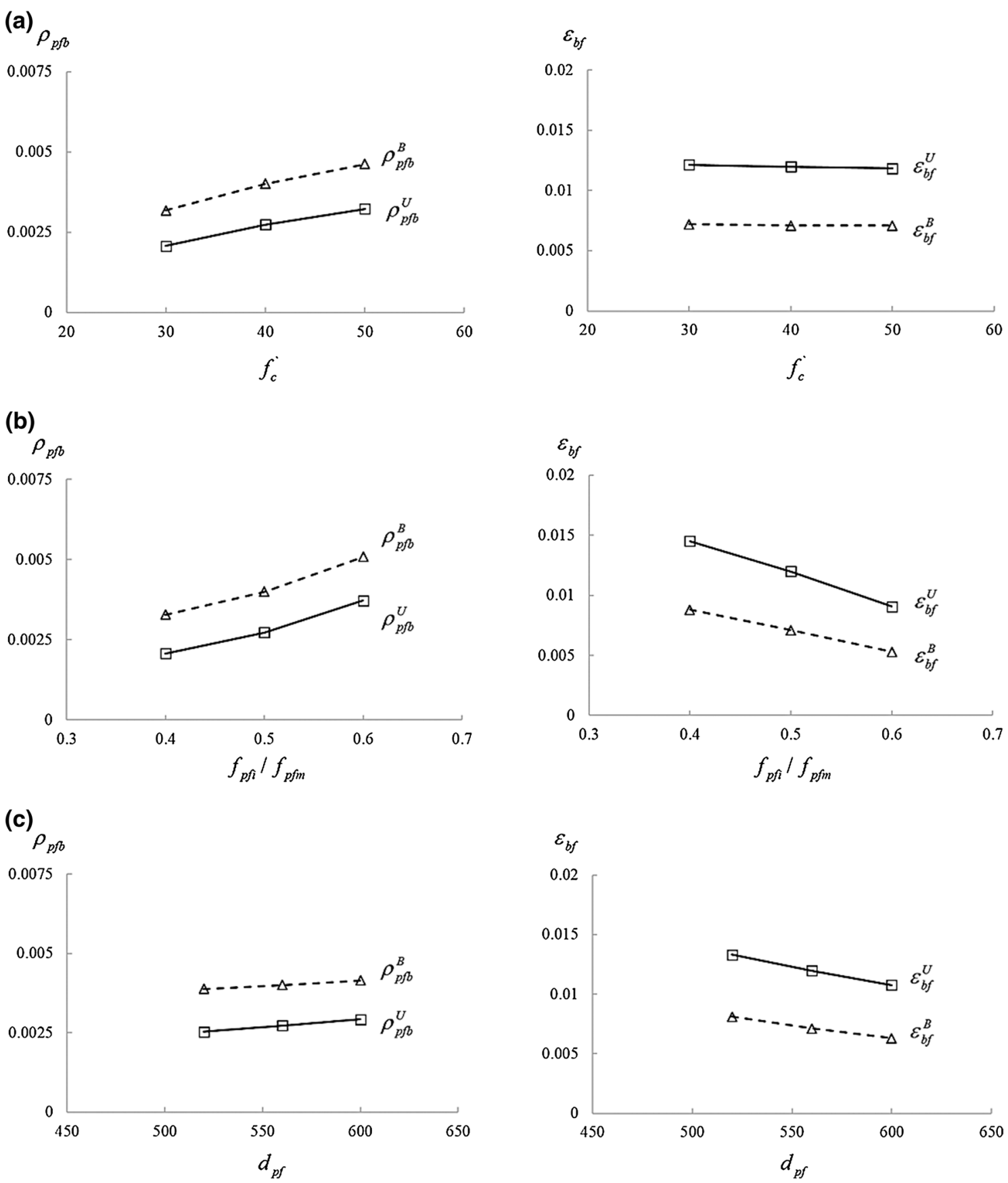

Fig. 9 Effects of main parameter on $\rho_{p f b}$ and $\varepsilon_{b f}$. a Concrete compressive strength $\left(f_{c}^{\prime}\right)$. b Initial prestress $\left(f_{p f i} / f_{p f m}\right)$. c Effective depth $\left(d_{p f}\right)$. d Amount of bonded rebar $\left(A_{b f}\right)$. e Relative distance between loading points, $L_{p} / L$.

\subsection{Effect of $f_{p f i}$}

As shown in Fig. $9 \mathrm{~b}$, the increase in $f_{p f i}$ resulted in an increase in both $\rho_{p f b}^{B}$ and $\rho_{p f b}^{U}$. With a larger value of $f_{p f i}$, less additional tensile strain on the tendon is available at the ultimate state for the balanced beam. This increases the depth of the neutral axis, increasing the area of concrete in compression; hence, the sectional area of tendon increases with the increase in $f_{p f i}$ for the sectional equilibrium.

\subsection{Effect of $\boldsymbol{d}_{p f}$}

In Fig. 9c, increasing tendencies for both $\rho_{p f b}^{B}$ and $\rho_{p f b}^{U}$ and deceasing tendencies for the strains of auxiliary bonded rebars were observed with an increase in $d_{p f}$. Since the amount of available tensile strain in the tendon in addition to its initial strain is the same regardless of the $d_{p f}$, an increase in $d_{p f}$ increases the sectional area of concrete in compression due to the increased depth of neutral axis and decreases the strain of the auxiliary bonded re-bars. Equilibrium at a section, therefore, requires a larger sectional area of tendon with a larger $d_{p f}$.

\subsection{Effect of $A_{b f}$}

Figure 9d illustrates that with the increase in $A_{b f}$, both $\rho_{p f b}^{B}$ and $\rho_{p f b}^{U}$ decrease while the strain of auxiliary bars remains almost constant. As $A_{b f}$ increases, the tensile resistance of bonded auxiliary bars increases. For the beam prestressed 

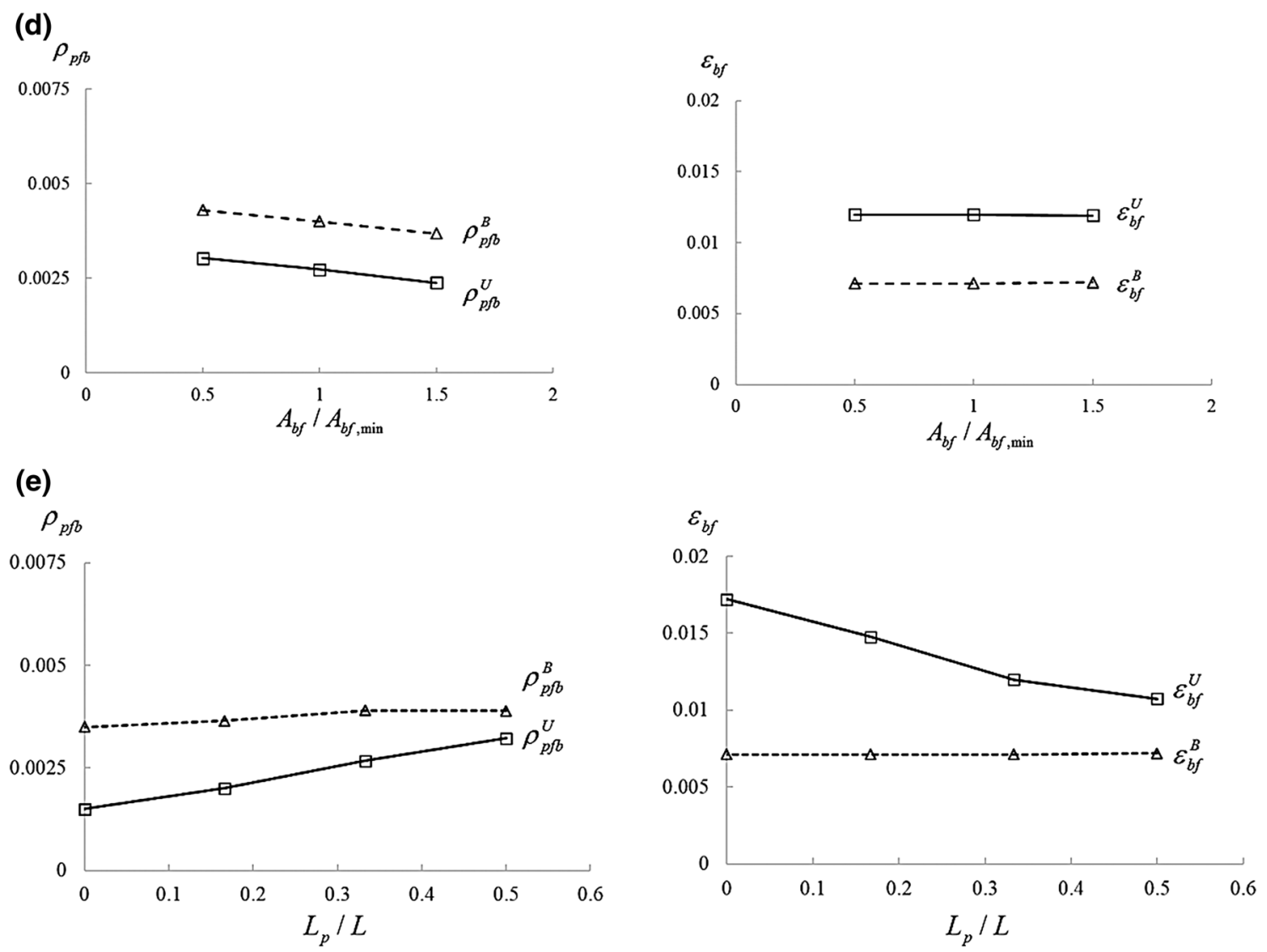

Fig. 9 continued

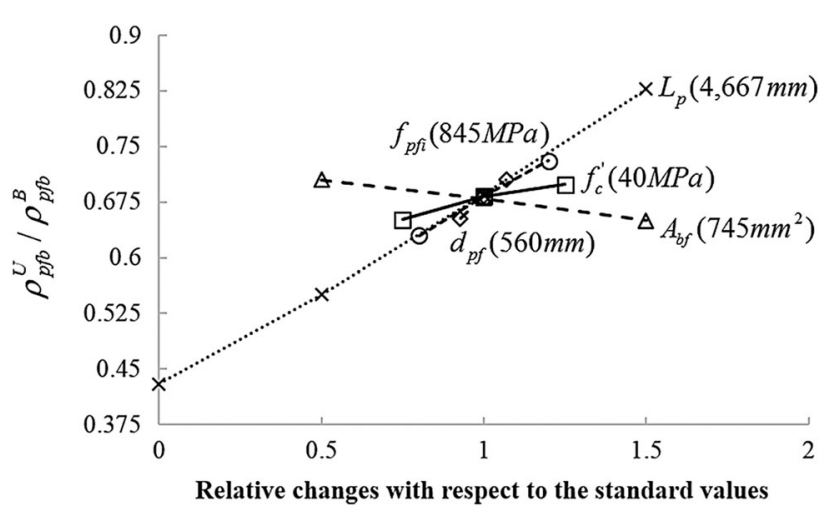

Fig. 10 Relative effects of parameters on $\rho_{p f b}^{U} / \rho_{p f b}^{B}$ (Values in parenthesis represent standard ones in Table 5).

with bonded tendon, as the area of $A_{b f}$ increases, the area of bonded tendon reduces to satisfy sectional equilibrium without change in strain configuration corresponding to the balanced condition. A similar explanation can also be applicable to an unbonded case even though there would be some changes in strain configuration at balanced condition with the increase of $A_{b f}$ due to the member-dependency of $\varepsilon_{p f u}$.

\subsection{Effect of $L_{p} / L$}

The effect of $L_{p} / L$ is presented in Fig. 9e. When the ratio of $L_{p} / L$ increases, the value of $\rho_{p f b}^{U}\left(\varepsilon_{b f}^{U}\right)$ tends to increase (decrease) in an almost linear fashion. Decrease in the value of $\varepsilon_{b f}^{U}$ with the increase in $L_{p} / L$ implies less curvature at critical sections, beam deflection, and $\varepsilon_{p f u}$ at ultimate state with the increase in $L_{p} / L$. Consequently, a greater area of $A_{p f u}$ is needed with a smaller value of $\varepsilon_{p f u}$ to balance a compressive resultant in a section resulting from a smaller curvature as $L_{p} / L$ increases.

In Fig. 10, the relative effects of each parameter on $\rho_{p f b}^{U} / \rho_{p f b}^{B}$ is illustrated based on the previous parametric studies. As shown in Table 5, the values of $\rho_{p f b}^{U} / \rho_{p f b}^{B}$ were shown to be between 0.43 to 0.83 . A relatively small value of $\rho_{p f b}^{U} / \rho_{p f b}^{B}$ suggests that a beam prestressed with an unbonded tendon and its reinforcement ratio greater than the balanced ratio $\left(\rho_{p f}^{U} \geq \rho_{p f b}^{B}\right)$ would fail in a more desirable compression-controlled mode with sufficient safety. It can be observed in Fig. 10 that increase in $\rho_{p f b}^{U}$ was more heavily influenced by increases in $L_{p}, d_{p f}, f_{p f i}$, and $f_{c}^{\prime}$ in this order. However, the increase in $A_{b f}$ resulted in the decrease in $\rho_{p f b}^{U}$.

\section{Conclusions}

The following conclusions are drawn from this study.

(1) The model based on three equivalent curvature blocks was validated by comparing its predictions with test results: the average and standard deviation of the ratios of the predicted to the measured beam strengths (total strain of unbonded tendon) at the ultimate state were 0.96 and 0.09 (1.07 and 0.06), respectively. 
(2) Performing regression analysis on the values of $\Delta f_{p s}$ generated by the model, a practical formula based on the concept of bond reduction factor was suggested for the estimation of $\Delta f_{p s}$. The formula predicted test results and model simulated values with reasonable accuracy, regardless of type of auxiliary bonded bars and different values of $L_{p} / L$.

(3) Predictions made by the equation provided by ACI 440.4R-04 showed significant deviations from the test results and model predictions, particularly for the beams reinforced with unbonded CFRP tendons and auxiliary bonded CFRP bars.

(4) By extending the concept of three equivalent curvature blocks, a stable iterative algorithm in two-loop was developed to find fixed points for the member-dependent quantities of the $\rho_{p f b}^{U}$.

(5) It was found that the values of $\rho_{p f b}^{U} / \rho_{p f b}^{B}$ remained in a range between 0.43 and 0.83 for the beams considered in this parametric study. Relatively small values of $\rho_{p f b}^{U} / \rho_{p f b}^{B}$ imply that a beam prestressed with unbonded tendons would fail in a compression-controlled mode with sufficient margin of safety if prestressed with $\rho_{p f}^{U} \geq \rho_{p f b}^{B}$.

(6) From the parametric studies, an increase in $\rho_{p t b}^{U}$ was more heavily influenced by increases in $L_{p}, d_{p f}, f_{p f i}$, and $f_{c}^{\prime}$ in order. However, the increase in $A_{b f}$ resulted in the decrease in $\rho_{p f b}^{U}$.

(7) The suggested model for $\rho_{p f b}^{U}$ can be of useful guide for a cost-effective design with minimum amount of unbonded CFRP tendons for compression-controlled beam section, avoiding a catastrophic failure resulting from undesired tensile fracture of tendons.

\section{Acknowledgments}

This research was supported by the Chung-Ang University Research Scholarship Grants in 2016.

\section{Open Access}

This article is distributed under the terms of the Creative Commons Attribution 4.0 International License (http://creativecommons.org/licenses/by/4.0/), which permits unrestricted use, distribution, and reproduction in any medium, provided you give appropriate credit to the original author(s) and the source, provide a link to the Creative Commons license, and indicate if changes were made.

\section{Appendix}

\section{Example of Finding $\Delta \varepsilon_{p f u}$ with and without Frictional Loss}

The specimen TB45 is considered. For this beam, $\varepsilon_{p f m}, \varepsilon_{p f i}$ and $\varepsilon_{d c}$ are given as $0.018,0.0081$ and 0.0003 , respectively.
It is assumed that $\eta=0.264 / \mathrm{rad}$. for curvature frictional loss. No wobble frictional loss is assumed as the span of the beam is relatively short. In the following, values in parenthesis represent the $\Delta \varepsilon_{p f u}$ values obtained without frictional loss. Tolerance is given by 0.01 . Units of length, moment, rotational angle and curvatures are $\mathrm{mm}, \mathrm{kN} \mathrm{m}$, radian and $1 \times 10^{-6} / \mathrm{mm}$, respectively.

\section{Iteration 1}

(1) Let $\alpha=0.5$. Obtain the assumed $\Delta \varepsilon_{p f u, s}=$ $\alpha \cdot\left\{\varepsilon_{p f m}-\left(\varepsilon_{p f i}+\varepsilon_{d c}\right)\right\}=0.0048 \quad$ (Eq. (12a)) and $\varepsilon_{p f u, s, o}=\varepsilon_{p f i}+\varepsilon_{d c}+\Delta \varepsilon_{p f u, s}=0.0129$ (Eq. (12b)).

(2) $\left(M_{e s}, \phi_{e s}\right),\left(M_{c s}, \phi_{c s}\right)$ and $\left(M_{u s}, \phi_{u s}\right)=(15.5,1.9)$, $(42.6,21)$ and $(68.6,720)$ by Eqs. (6), (7) and (11), respectively.

(3) Obtain $\phi_{e q}=550$ and $L_{e q}=535$ (Eq. 2). $\Delta_{e q}=9.88$, $\Delta_{p}=5.96$ (Eq. (3)) and $\Delta \varepsilon_{p f u}=\frac{\Delta_{e q}+\Delta_{p}}{L}=0.00545$ (Eq. 5).

(4) $\theta_{u s}=\frac{1}{2} \cdot \phi_{u} \cdot L_{p}=0.018 \quad$ and $\quad \theta_{s}=\theta_{u s}+$ $\int_{L_{p} / 2}^{L_{s}} \phi_{e q} \cdot\left\langle\frac{L_{s}-L_{p} / 2}{L_{e q}}-1\right\rangle \cdot d x=0.066$ and 0.066 for "s" =" es" and "cs", respectively (Eq. (13a)).

$\Delta \varepsilon_{p f u, s}=e^{-\left(\kappa \cdot L+\eta \cdot \theta_{s}\right)} \cdot \Delta \varepsilon_{p f u}=0.00536(0.00545)$,

$0.00536 \quad(0.00545)$ and $0.00543 \quad(0.00545)$ for

"s" =" es," "cs" and "us," respectively (Eq. (13b)).

(5) $\varepsilon_{p f u, s, n}=\varepsilon_{p f i}+\varepsilon_{d c}+\Delta \varepsilon_{p f u, s}=0.01376(0.01385)$, $0.01376 \quad(0.01385)$ and $0.01383(0.01385)$ for "s" =" es," "cs" and "us," respectively.

(6) $\left|\frac{\varepsilon_{p f u, s, n}-\varepsilon_{p f i, s, o}}{\varepsilon_{p p u, s, o}}\right|=0.12,0.12$ and 0.13 for " $\mathrm{s}$ " = "es," "cs" and "us," respectively.

$$
\begin{aligned}
\max \left|\frac{\varepsilon_{p f u, s, n}-\varepsilon_{p f u, s, o}}{\varepsilon_{p f u, s, o}}\right| & =\left|\frac{\varepsilon_{p f u, s, n}-\varepsilon_{p f u, s, o}}{\varepsilon_{p f u, s, o}}\right| \\
& =0.13>0.01 \text { (=tolerance) } .
\end{aligned}
$$

Let $\quad \varepsilon_{p f u, s, o}=\varepsilon_{p f u, s, n}=0.01376(0.01385), \quad 0.01376$ (0.01385) and $0.01383(0.01385)$ for "s"="es, "cs" and “us," respectively. Repeat from step 2) in iteration 2.

\section{Iteration 2}

(2) $\left(M_{e s}, \phi_{e s}\right),\left(M_{c s}, \phi_{c s}\right)$ and $\left(M_{u s}, \phi_{u s}\right)=(16.2,1.8)$, $(43.2,20)$ and $(69.8,710)$ by Eqs. (6), (7) and (11), respectively.

(3) Obtain $\phi_{e q}=540$ and $L_{e q}=541$ (Eq. (2)). $\Delta_{e q}=9.70$, $\Delta_{p}=5.85$ (Eq. (3)) and $\Delta \varepsilon_{p f u}==0.00535$ (Eq. (5)).

(4) $\theta_{u s}=0.017$ and $\theta_{s}=0.064$ and 0.064 for " $\mathrm{s} "=$ " es" and "cs", respectively (Eq. (13a)).

$\Delta \varepsilon_{p f u, s}=0.00532(0.00535), 0.00526(0.00535)$ and $0.00526(0.00535)$ for "s" $=$ " es, " cs" and "us, " respectively (Eq. (13b)).

(5) $\varepsilon_{p f u, s, n}=0.01366(0.01374), 0.01366(0.01374)$ and $0.01372(0.01374)$ for "s"="es," "cs" and "us," respectively.

(6) $\left|\frac{\varepsilon_{p f i, s, n}-\varepsilon_{p f u, s, o}}{\varepsilon_{p f u, s, o}}\right|=0.007,0.007$ and 0.008 for “s”="es," "cs" and "us," respectively. $\max \left|\frac{\varepsilon_{p f u, s, n}-\varepsilon_{p f u, s, o}}{\varepsilon_{p f u, s, o}}\right|=\left|\frac{\varepsilon_{p p u, s, n}-\varepsilon_{p f u, s, o}}{\varepsilon_{p f u, s, o}}\right|=0.008<0.01$ 
(= tolerance) then the strain of unbonded tendon is converged with $\varepsilon_{p f u, u s}=\varepsilon_{p f u, u s, n}=0.01366$ (0.01374), $0.01366(0.01374)$ and $0.01372 \quad(0.01374)$ for "s"="es," "cs" and "us," respectively. Stop iteration.

\section{References}

ACI Committee 318. (2014). Building code requirements for structural concrete and commentary (ACI 318-14). Farmington Hills, MI: American Concrete Institute.

Alkhairi, F. M. (1991). On the behavior of concrete beams prestressed with unbonded internal and external tendon, Ph.D. thesis, University of Michigan, Ann Arbor, MI.

American Concrete Institute (ACI). (2003). Guide for the design and construction of concrete reinforced with FRP bars (ACI 440.1R-03). American Concrete Institute, Farmington Hills, MI.

American Concrete Institute (ACI). (2011). Prestressing concrete structures with FRP tendons (ACI 440.4R-04), American Concrete Institute, Farmington Hills, MI.

Du, J. S., Au, F. T. K., Cheung, Y. K., \& Kwan, A. K. H. (2008). Ductility analysis of prestressed concrete beams with unbonded tendons. Engineering Structures, 30(1), 13-21.

Elrefai, A., West, J., \& Soudki, K. (2012). Fatigue of reinforced concrete beams strengthened with externally post-tensioned CFRP tendons. Construction and Building Materials, 29, 246-256.

Girgle, F., \& Petr, Š. (2016). An anchoring element for prestressed FRP reinforcement: simplified design of the anchoring area. Materials and Structures, 49(4), 1337-1350.

Grace, N. F., Enomoto, T., Sachidanandan, S., \& Puravankara, S. (2006). Use of CFRP/CFCC reinforcement in prestressed concrete box-beam bridges. ACI Structural Journal, 103(1), 123-132.

Grace, N. F., Singh, S. B., Puravankara, S., Mathew, S. S., Enomoto, T., Mohti, A. A., et al. (2008). Flexural behavior of precast concrete post-tensioned with unbonded, carbonfiber-composite cables. Precast/Prestressed Concrete Institute Journal, 92(6), 62-81.

Han, Q., Wang, L., \& Xu, J. (2015). Experimental research on mechanical properties of transverse enhanced and hightemperature-resistant CFRP tendons for prestressed structure. Construction and Building Materials, 98, 864-874.

Harajli, M. H. (1990). Effect of span-depth ratio on the ultimate steel stress in unbondedprestressed concrete members. ACI Structural Journal, 87(3), 305-312.

Heo, S., Shin, S., \& Lee, C. (2013). Flexural behavior of concrete beams internally prestressed with unbonded carbon- fiber-reinforced polymer tendons. Journal of Composites for Construction, 17(2), 167-175.

Jeon, S. J., Park, S. Y., Kim, S. H., Kim, S. T., \& Park, Y. H. (2015). Estimation of friction coefficient using smart strand. International Journal of Concrete Structures and Materials, 9(3), 369-379.

Kato, T., \& Hayashida, N. (1993). Flexural characteristics of prestressed concrete beams with CFRP tendons. International Symposium Fiber Reinforced Plastic Reinforcement for Concrete Structures, ACI Special Publication, 138-26, 419-440.

Kent, D. C., \& Park, R. (1971). Flexural members with confined concrete. Journal of the Structural Division ASCE, 97(7), 1969-1990.

Lee, L. M., Moon, J. H., \& Lim, J. M. (1999). Proposed methodology for computing of unbonded tendon stress at flexural failure. ACI Structural Journal, 96(6), 1040-1048.

Lee, C., Ko, M., \& Lee, Y. (2013) Bend strength of complete closed-type carbon fiber-reinforced polymer stirrups with rectangular section. Journal of Composites for Construction. 18(1).

Lee, C., Lee, S., \& Shin, S. (2015a) "Shear capacity of RC beams with carbon fiber-reinforced polymer stirrups with rectangular section”, Journal of Composites for Construction, 04015085 .

Lee, C., Shin, S., \& Lee, S. (2015b). Modelling of load-deflection of concrete beams internally prestressed with unbonded CFRP tendon. Magazine of Concrete Research, 67(13), 730-746.

Maissen, A., \& De Smet, C. A. M. (1995). Comparison of concrete beams prestressed with carbon fibre reinforced plastic and steel strands, non-metallic (FRP) reinforcement for concrete structures (pp. 430-439). Bagneux, France: RILEM.

Naaman, A. E., \& Alkhairi, F. M. (1991a). Stress at ulitmate in unbonded post-tensioning tendons : Part 1-Evaluation of the state-of-the-art. ACI Structural Journal, 88(5), 641-651

Naaman, A. E., \& Alkhairi, F. M. (1991b). Stress at ultimate in unbonded post-tensioning tendons: Part 2-Proposed methodology. ACI Structural Journal, 88(6), 683-692.

Nilson, A. H. (1987). Design of prestressed concrete (2nd ed.). Hoboken, NJ: Willey.

Sivaleepunth, C., Niwa, J., Bui, D. K., Tamura, S., \& Hamada, Y. (2006). Prediction of tendon stress and flexural strength of externally prestressed concrete beams. Doboku Gakkai Ronbunshu E, 62(1), 260-273.

Yu, T. L., \& Zhang, L. Y. (2011). Friction loss of externally prestressed concrete beams with carbon fiber-reinforced polymer tendons. Advanced Materials Research, 163, 3701-3706. 